\title{
Portfolio Optimization Problems in Different Input Data using Particle Swarm Optimization
}

\author{
Zeinodin Alizadeh \\ Department of Accounting \\ Kashan Branch \\ Islamic Azad University \\ Kashan, Iran
}

\author{
Hossein Panahian \\ Phd,Department of Accounting \\ Kashan Branch \\ Islamic Azad University \\ Kashan, Iran
}

\begin{abstract}
Portfolio optimization and diversification as a tool for development and understanding of financial markets have been entered in financial management topics for guide investors to make appropriate decision. Markowitz's modern portfolio theory (MPT) has been the most successful achievement in this field. Since, stock has a non-linear behavior in stock market; the need to non-linear models in order to identify the behavior of stock in relation to portfolio's optimum selection should be felt. Because of successful performance of evolutionary algorithms, these algorithms can provide suitable methods for investors. In this paper, particle swarm optimization (PSO) algorithm employed to select optimum portfolio. Proposed approach was tested on monthly and yearly data set of fifty top companies accepted in Tehran Stocks Exchange which were collected from March 2007 to September 2011. PSO performance compared with genetic algorithm (GA) and artificial bee colony algorithm (ABC) in term of Sharp ratio. The computational results show that the PSO algorithm impressively outperforms $\mathrm{GA}$ and $\mathrm{ABC}$, and monthly data is better criterion than yearly data in portfolio selection.
\end{abstract}

\section{Keywords}

Portfolio Optimization, Modern Portfolio Theory, Particle Swarm Optimization, Sharpe Ratio.

\section{INTRODUCTION}

Harry Markowitz [1] who introduced mean - variance model in the March 1952 issue of the journal of finance initiated a new approach in the portfolio optimization problem and as a matter of fact, we can say he created revolution in investment management topics. In the portfolio optimization, we want to find the optimum way of investing a particular amount of money in a given set of securities or assets [2]. Indeed, the target is to select asset which minimize the risk and maximize the return in portfolio optimization. Although, achieve to minimum risk and maximum return looks simple, the way of determining an optimum portfolio is more than one. The fundamental rule of a mean-variance portfolio structure explains the compromises between mean and variance, depicting expected returns and risk of a portfolio [3].

The portfolio optimization model is a mixed integer programming and quadratic problem. The main drawback of this method is the time needed to compute the covariance matrix from historical data and the difficulty of solving when total number of available assets in portfolio is high. By employing many techniques, several researchers have tried to find this problem, but exact solution methods fail to solve large-scale instances of the problem. Therefore, several researchers try to improve algorithms by using the up to date mathematical programming methodology (like neural network and evolutionary algorithm) to solving portfolio problems. These techniques are able to find high-quality solutions in a reasonable amount of time. Some evolutionary algorithm based on Genetic Algorithm (GA) [4, 2, 5, 6], Tabu Search (TS) [4, 7], Simulated Annealing (SA) [4, 8, 9], neural networks [3] and others [10,11, 12] have been reported in the literatures for the standard Markowitz portfolio selection problem.

In this paper, we propose a heuristic method based on PSO to solve the Markowitz portfolio selection model. The rest of the paper is organized as follows. Section 2 describes models for portfolio optimization. In Section 3, the background of PSO is summarized. The research result performed in Section 4. Conclusions researches are drawn in Section 5.

\section{PORTFOLIO SELECTION PROBLEM}

One of the main characteristics of capital markets is uncertainty and price volatility and stock return of companies which have worried investors about their investment future. In order to reduce these concerns and greater inclusion of individuals in capital markets about continuity and increasing of its life, an important solution is to select the appropriate securities investment and to form the portfolio, until in this way investment venture comes to the least in the capital market.

According to the importance of portfolio selection, capital markets researchers have made extensive efforts for providing stock analyzing methods in financial market. These efforts led to the creation of new methods and models which have been in financial issues that its origin has been Harry Markowitz Modern Portfolio Theory (MPT).

Markowitz proposed a problem as a quadratic programming with the aim of minimizing the variance of the asset with the condition that the expected return is equal to a constant value. The main premise of this model is that all investors are risk averse. It has also a functional limitation based on the total weight of an asset that should be equal to one. In addition, weight of each asset in the portfolio must be between zero and one and non-negative numbers.

\section{2-1. Mean-variance model}

In this section, the well-known mean-variance model is introduced. The mean-variance model for portfolio optimization problem is: 
$\operatorname{Minimize} \sum_{i=1}^{N} \sum_{j=1}^{N} w_{i} w_{j} \sigma_{i j}$

Subject to $\sum_{i=1}^{N} w_{i} r_{i}=R$

$\sum_{i=1}^{n} w_{i}=1$

$0 \leq w_{i} \leq 1$

where $N$ is the number of available assets, $r_{i}$ is the expected return of the asset $i, \sigma_{i j}$ is the covariance between assets $i$ and $j, w_{i}$ is the proportion held of the asset $i$ and $R$ is the expected return of the portfolio [13]. Problem (1) can be described as follows:

Minimize $\lambda\left[\sum_{i=1}^{N} \sum_{j=1}^{N} w_{i} w_{j} \sigma_{i j}\right]-(1-\lambda)\left[\sum_{i=1}^{N} w_{i} r_{i}\right]$

Subject to $\sum_{i=1}^{N} w_{i}=1$

$0 \leq w_{i} \leq 1 \quad(i, \ldots ., n)$

In the above model, $\lambda$ is a weighting parameter value changes in the interval $[0,1]$. So that by putting $\lambda=0$ the total amount of weight coefficient are assigned to return and the portfolio which has highest efficiency is selected and by considering $\lambda$ $=1$ the total amount of weight coefficient are assigned to variance and the portfolio which has the lowest efficiency, is selected. Finally, between zero and one, portfolio which has exchange relationship between risk and return, is optimized. Means by adding value of coefficient $\lambda$, the goal of risk reduction, becomes more important and at the same time, because the amount of 1- $\lambda$ is reduced, the goal of maximizing efficiency will be lower.

\section{2-2. Sharpe ratio model}

Frequently, researchers focus on efficient frontier in portfolio optimization. Rather than tracing the efficient frontier, we attempt to optimize the portfolio Sharpe ratio (RVAR) [14]. The information from mean and variance of an asset are combined in Sharpe ratio. RVAR is ordinal scale and portfolios are simply gradable and comparable with this measure. So, we can use it to evaluate the performance of a portfolio. RVAR described with the following equation:

$R V A R=\frac{T R_{p(a v r)}-R F_{p(a v r)}}{S D_{p}}$

where $T R_{p(a v r)}$ is the mean return of the portfolio, $R F_{p(a v r)}$ is the rate of return of a risk-free security (In this study we consider it $14 \%$ ) and $S D_{p}$ is the standard deviation of $T R_{p(a v r)}$. We can maximize the portfolio RVAR effectively by balancing the compromise between maximizing the expected return and minimizing the risk by modifying the portfolios weight $w_{i}$. In this study, we are trying to use RVAR and applying PSO to identify the best combination of selected stocks in the portfolio.

\section{PARTICLE SWARM OPTIMIZATION}

The PSO algorithm which proposed by Kennedy and Eberhart [15], inspired by the behavior of the social organisms such as flock of birds. Similar to other population-based algorithms, such as genetic algorithms, the PSO algorithm is initialized with a population of random solutions, called particles. These particles moves over the search space with an adaptable velocity, and record the best position it has discovered in the search space. Each particle can adjust its velocity vector, based on its own flying experience and the flying experience of the other particles in the search space. Suppose that the dimension for a searching space is $D$, the total number of particles is $N$. The position and the velocity of the $i$ th particle can be represented as vector $X_{i}=\left(x_{i 1}, x_{i 2}, \ldots, x_{i D}\right)$ and $V_{i}=\left(v_{i 1}, v_{i 2}, \ldots, v_{i D}\right)$, respectively. The best previous position of the $i$ th particle is $P_{i}=\left(p_{i 1}, p_{i 2}, \ldots, p_{i D}\right)$, and the best previous of the swarm is $P_{g}=\left(p_{g 1}, p_{g 2}, \ldots, p_{g D}\right)$. Then, the velocity of the particle and its new position will be determined according to the following two equations:

$$
\begin{aligned}
& V_{i d}(t+1)=V_{i d}(t)+c_{1} r_{1}\left[P_{i d}-X_{i d}(t)\right]+c_{2} r_{2}\left[P_{g d}-X_{i d}(t)\right] \\
& X_{i d}(t+1)=X_{i d}(t)+V_{i d}(t+1)
\end{aligned}
$$

where $c_{1}$ and $c_{2}$ are the individual and social learning rates, respectively, and $r_{1}$ and $r_{2}$ are random numbers in the range 0 and 1 with uniformly distribution.

It is found that usually the particles velocities build up too fast and they may converge to a suboptimal solution. Shi and Eberhart [16] introduced the concept of inertia weight to the original version of PSO, in order to reduce the velocity. The velocity of the particle, with the inertia term expressed as follows:

$V_{i d}(t+1)=w V_{i d}(t)+c_{1} r_{1}\left[P_{i d}-X_{i d}(t)\right]+c_{2} r_{2}\left[P_{g d}-X_{i d}(t)\right]$

where $\theta$ is the inertia weight, decreases linearly with the iteration number as follows:

$w_{i}=w_{\max }-\left(\frac{w_{\max }-w_{\min }}{i_{\max }}\right) i$

where $w_{\min }$ and $w_{\max }$ are the initial and final values of the inertia weight, respectively, $i$ is the current iteration number and $i_{\max }$ is the maximum number of iterations used in PSO. The values of $w_{\max }=0.9$ and $w_{\min }=0.4$ are the proper value through empirical studies [16]. Figure 1 shows the semi code of PSO. 


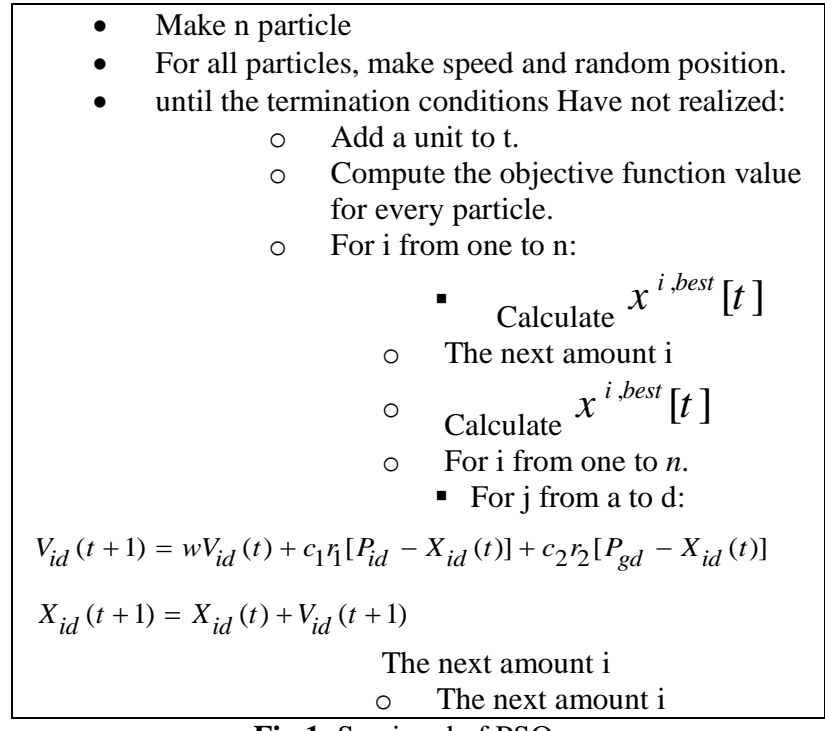

Fig 1: Semi cod of PSO

\section{RESEARCH RESULTS}

This study used PSO algorithm to select optimum portfolio. Returns of fifty top stocks accepted companies in Tehran Stocks Exchange are selected as case study which are collected from March 2007 to September 2011. The part of this data (from March 2007 to March 2011) used for selecting portfolio and other part (from April 2011 to September 2011) used for evaluating the performance of portfolios. The proposed approach has been compared to two other approaches, GA and ABC in term of Sharpe ratio.

\section{4-1. Determine the input parameters}

In order to Implementation and evaluation of the proposed algorithm its codes written in MATLAB software and was implemented. Before running the algorithm, its parameters should be determined based on literature and past research. These values have been determined in this study as follows:

\section{4-1-1. Particle swarm algorithm parameters}

In this algorithm the number of particles and the maximum number of cycles $(\mathrm{MCN})$ has been considered 50 and 100, respectively. The individual and social learning rate equal to 2 and $r_{1}, r_{2}$ are random numbers in the interval $[0,1]$ with the uniform distribution.

\section{4-1-2. Genetic algorithm parameters}

Population size and maximum number of generation in this algorithm is selected 50 and 100, respectively. Selection techniques used is the roulette wheel selection technique. The uniform mutation operator is used with a 0.5 rate. Intersection operator is median intersection operator with a 0.5 rate.

\section{4-1-3. Artificial bee colony algorithm parameters}

The maximum number of iterations equal to 100 , colony size is considered 50. The number of spectators and the worker bees is chosen $50 \%$ colony size and number of scout bees is one selected.
In addition to input parameters of algorithms, the coefficient of risk aversion $(\lambda)$ which is a constant coefficient in the interval $[0,1]$, related to the portfolio optimization problem must be determined. In this study, $\lambda$ has been considered 0.5 .

\section{4-2. Evaluation of the stability of the algorithm}

The evaluation of the stability of the algorithm is one of the important tests that should be done. Whether the algorithm gives the same answer each time, as well as the uniqueness of the optimal solution, is an important point that should be examined. To this end, PSO algorithm was run several times. Then, these answers were compared with each other. The results of ten times performing the algorithm are shown in table 1 and figure 1 .

Table 1: Checking the stability of the PSO in 10 times algorithm run

\begin{tabular}{|c|c|c|c|c|c|}
\hline $\begin{array}{c}\text { Total } \\
\text { Average }\end{array}$ & $\begin{array}{c}\text { Objective } \\
\text {. Value } \\
\text { Run 5 }\end{array}$ & $\begin{array}{c}\text { Objective } \\
\text {. Value } \\
\text { Run 4 }\end{array}$ & $\begin{array}{c}\text { Objective } \\
\text {. Value } \\
\text { Run } 3\end{array}$ & $\begin{array}{c}\text { Objective } \\
\text {. Value } \\
\text { Run 2 }\end{array}$ & $\begin{array}{c}\text { Objective } \\
\text {. Value } \\
\text { Run 1 }\end{array}$ \\
\hline-0.0332 & -0.0325 & -0.0382 & -0.0225 & -0.0299 & -0.0455 \\
\hline Variance & $\begin{array}{c}\text { Objective } \\
\text {. Value } \\
\text { Run 10 }\end{array}$ & $\begin{array}{c}\text { Objective } \\
\text {.Value } \\
\text { Run 9 }\end{array}$ & $\begin{array}{c}\text { Objective } \\
\text {. Value } \\
\text { Run } 8\end{array}$ & $\begin{array}{c}\text { Objective } \\
\text {.Value } \\
\text { Run 7 }\end{array}$ & $\begin{array}{c}\text { Objective } \\
\text {. Value } \\
\text { Run 6 }\end{array}$ \\
\hline $\begin{array}{c}0.000051 \\
4\end{array}$ & -0.0318 & -0.0438 & -0.0310 & -0.0291 & -0.0282 \\
\hline
\end{tabular}

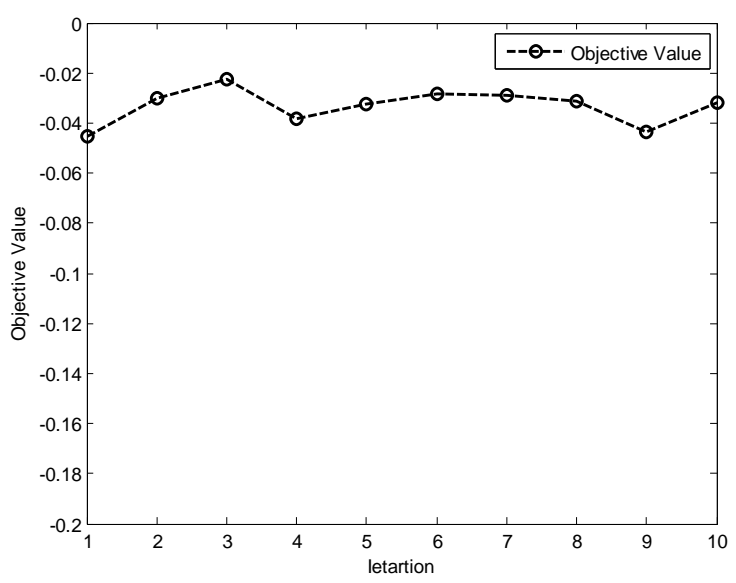

Fig 2: Check the stability of the PSO in 10 times algorithm run

The results indicate little difference between the answers from different iterations. Variance for the objective function value is 0.0000514 which was a very small and it reflects the high stability of the algorithm in different runs.

\section{4-3. Computational result}

After being assured of the stability of PSO, this algorithm along with $\mathrm{GA}$ and $\mathrm{ABC}$ is run based on mean- variance model and monthly and yearly input data. In order to evaluate the portfolios performance, the six-month return of fifty top companies is used as a test data. Table 2 shows the return of portfolios on six-month test period and breakdown of each month. 
Table 2: The return of portfolios on six-month test period

\begin{tabular}{|c|c|c|c|c|c|c|c|}
\hline \multicolumn{6}{|c|}{ Return of Test Period } & \multirow{2}{*}{$\begin{array}{l}\text { Input } \\
\text { Data }\end{array}$} & \multirow{2}{*}{ Algorithm } \\
\hline September & August & July & June & May & April & & \\
\hline 9.11 & 2.57 & 0.14 & -2.09 & 1.5 & 9.11 & Monthly & PSO \\
\hline 11.46 & -0.04 & -0.04 & -6.07 & 3.45 & 9.54 & Yearly & PSO \\
\hline 11.49 & 4.15 & -0.99 & -4.71 & -0.38 & 7.44 & Monthly & GA \\
\hline 9.64 & 3.11 & -1.94 & -5.56 & -0.77 & 7.68 & Yearly & GA \\
\hline 8.41 & 1.43 & -1.33 & -4.48 & 0.70 & 14.36 & Monthly & $\mathrm{ABC}$ \\
\hline 7.58 & 2.48 & -0.74 & -3.99 & -0.44 & 7.96 & Yearly & $\mathrm{ABC}$ \\
\hline
\end{tabular}

To calculate RVAR, the return of portfolios that were shown in the tables 2 and also Eq. (3) was used. Table 3 shows the results of expected return, variance of portfolios, mean returns of portfolio in six-month test period, standard deviation of returns in test period and RVAR.

Table 3: Result of different models

\begin{tabular}{|c|c|c|c|c|c|c|}
\hline RVAR & $\begin{array}{c}\text { Std. Dev. of } \\
\text { portfolio's } \\
\text { returns }\end{array}$ & $\begin{array}{c}\text { Mean } \\
\text { returns of } \\
\text { portfolio }\end{array}$ & $\begin{array}{c}\text { Variance } \\
\text { of } \\
\text { portfolio }\end{array}$ & $\begin{array}{c}\text { Expected } \\
\text { Return of } \\
\text { Portfolio }\end{array}$ & $\begin{array}{c}\text { Input } \\
\text { Data }\end{array}$ & Algorithm \\
\hline 0.47 & 4.70 & 3.39 & 0.001 & 0.046 & Monthly & PSO \\
\hline 0.28 & 6.56 & 3.05 & 0.102 & 0.478 & Yearly & PSO \\
\hline 0.28 & 6.00 & 2.83 & 0.002 & 0.040 & Monthly & GA \\
\hline 0.19 & 5.64 & 2.23 & 0.084 & 0.419 & Yearly & GA \\
\hline 0.29 & 6.94 & 3.18 & 0.003 & 0.032 & Monthly & ABC \\
\hline 0.20 & 4.82 & 2.14 & 0.078 & 0.463 & Yearly & ABC \\
\hline
\end{tabular}

\section{CONCLUSION}

In this paper, we used PSO algorithm to optimize the portfolio. The introduced method was tested on monthly and yearly data of fifty top companies accepted in Tehran Stocks Exchange. To evaluate the performance of the PSO, this algorithm compared with GA and ABC. The Sharpe ratio was used as a criterion for this comparison. The experimental results show the efficiency of the PSO in the portfolio optimization problem. Also, portfolios which were made based on monthly data have better performance than yearly data.

\section{REFERENCES}

[1] Markowitz, H. M. 1952. Portfolio selection. J Finance 7:77-91.

[2] Fernandez, A. and Gomez, S. 2007. Portfolio selection using neural networks, Computers \& Operations Research 34, 1177-1191.

[3] Oh, K.J., Kim, T.Y. and Min, S. 2005. Using genetic algorithm to support portfolio optimization for index optimizer." in: Proc. of IEEE World Conf. on Computation fund management, Expert Systems with Applications 28, 371-379.

[4] Chang, T.J., Meade, N., Beasley, J.E., and Sharaiha, Y.M. 2000. Heuristics for cardinality constrained portfolio optimization, Computers \& Operations Research 27, 1271-1302.

[5] Yang, X. 2006 .Improving portfolio efficiency: A genetic algorithm approach, Computational Economics 28, 1-14.

[6] Loraschi, A., Tettamanzi, A., Tomassini, M., Svizzero, C., Scientifico, C., \& Verda, P. 1995. Distributed genetic algorithms with an application to portfolio selection. In D. W. Pearson, N. C. Steele, \& R. F. Albrecht (Eds.), Proceedings of the international conference on artificial neural networks and genetic algorithms (ICANNGA95) (pp. 384-387). Berlin: Springer-Verlag.

[7] Rolland, E. 1996. A tabu search method for constrained real-number search: Applications to portfolio selection. Columbus: Ohio State University, Department of Accounting \& Management Information Systems.

[8] Crama, Y. and Schyns, M. 2003. Simulated annealing for complex portfolio selection problems, European Journal of Operational Research 150, 546-571.

[9] Derigs, U. and Nickel, N.H. 2004. On a local-search heuristic for a class of tracking error minimization problems in portfolio management, Annals of Operations Research 131, 45-77.

[10] Mansini, R. and Speranza, M.G. 1999. Heuristic algorithms for the portfolio selection problem with minimum transaction lots, European Journal of Operational Research 114, 219-233.

[11] Derigs, U. and Nickel, N.H. 2003. Meta-heuristic based decision support for portfolio optimization with a case study on tracking error minimization in passive portfolio management, OR Spectrum 25, 345-378.

[12] Schlottmann, F. and Seese, D. A. 2004. hybrid heuristic approach to discrete multi-objective optimization of credit portfolios, Computational Statistics \& Data Analysis 47, 373-399.

[13] Chang, T., Meade, T., Beasley, J.E. and Sharaiha , Y.M. 2000. Heuristics for Cardinality constrained Portfolio Optimization .Computer \& Operations Research, 27. 12711302.

[14] Sharpe, W. F. 1966. Mutual fund performance. The Journal of Business, 39, 119-138.

[15] Eberhart, R. C., and Kennedy, J. 1995. "A New Optimizer Using Particle Swarm Theory.” Proceedings of the 6th International Symposium on Micro Machine and Human Science. Nagoya, Japan 39-432.

[16] Shi Y.H., Eberhart R.C. 1998. "A modified particle swarm

69-73. 